\title{
On crack tunneling and plane-strain delamination in laminates
}

\author{
René C. Alderliesten
}

Received: 23 October 2007 / Accepted: 28 April 2008 / Published online: 16 May 2008

(C) The Author(s) 2008

\begin{abstract}
Previous numerical work on crack tunnelling and plane-strain delamination in layered solids is evaluated with static and fatigue experiments and analysis. It is concluded that the translation of the theory derived for static fracture to fatigue loading is not as straightforward as initially assumed. Details such as delamination location, stress state, plasticity and modemixity need further consideration to obtain a theory that is sufficiently adequate to describe the static and fatigue phenomena observed in practice.
\end{abstract}

Keywords Cracking - Delamination · Fibre metal laminates

\section{Nomenclature}

\begin{tabular}{|c|c|c|}
\hline $\mathrm{a}$ & Tunnelling crack length & {$[\mathrm{mm}]$} \\
\hline$a_{s}$ & $\begin{array}{l}\text { Starter notch (sawcut) length } \\
\text { of tunnelling crack }\end{array}$ & {$[\mathrm{mm}]$} \\
\hline b & Delamination length & {$[\mathrm{mm}]$} \\
\hline $\mathrm{db} / \mathrm{dN}$ & Delamination growth rate & [mm/cycle] \\
\hline $\mathrm{E}_{\mathrm{al}}$ & $\begin{array}{l}\text { Young's modulus of } \\
\text { aluminium }\end{array}$ & {$[\mathrm{MPa}]$} \\
\hline $\mathrm{E}_{\mathrm{f}, 0}$ & $\begin{array}{l}\text { Young's modulus of } 0^{\circ} \text { fibre } \\
\text { layers }\end{array}$ & {$[\mathrm{MPa}]$} \\
\hline $\mathrm{E}_{\mathrm{f}, 90}$ & $\begin{array}{l}\text { Young's modulus of } 90^{\circ} \text { fibre } \\
\text { layers }\end{array}$ & {$[\mathrm{MPa}]$} \\
\hline
\end{tabular}

R. C. Alderliesten ( $\square)$

Aerospace Materials and structures, Faculty of Aerospace Engineering, Delft University of Technology, P.O. Box 5058, 2600 GB Delft, The Netherlands e-mail: R.C.Alderliesten@tudelft.nl
$\mathrm{G}_{\mathrm{d}} \quad$ Strain energy release rate for delamination

$\mathrm{G}_{\mathrm{dc}} \quad$ Critical strain energy release rate for delamination

$\mathrm{G}_{\mathrm{I}} \quad$ Mode I strain energy release rate for tunnelling crack

$\mathrm{G}_{\mathrm{Ic}} \quad$ Critical mode I strain energy release rate for tunnelling crack

$\mathrm{K}_{\mathrm{d}} \quad$ Stress intensity factor for delamination

$\mathrm{K}_{\mathrm{I}} \quad$ Mode I stress intensity factor for tunnelling crack

$\mathrm{N} \quad$ Number of cycles

$\mathrm{n}_{\mathrm{al}} \quad$ Number of aluminium layers

$\mathrm{n}_{\mathrm{cr}}$

Number of cracked aluminium layers

$\mathrm{n}_{\mathrm{f}, 0} \quad$ Number of $0^{\circ}$ fibre layers

$\mathrm{n}_{\mathrm{f}, 90}$ number of $90^{\circ}$ fibre layers

$\mathrm{P} \quad$ Force

$\mathrm{t}_{\mathrm{al}} \quad$ Thickness of single aluminium layer

$\mathrm{t}_{\mathrm{f}, 0} \quad$ Thickness of single $0^{\circ}$ fibre layer

$\mathrm{t}_{\mathrm{f}, 90}$ Thickness of single $90^{\circ}$ fibre [mm] layer

$\mathrm{t}_{\text {lam }} \quad$ Total laminate thickness

$\mathrm{S}_{\text {lam }} \quad$ Gross laminate stress

$\mathrm{v}_{\mathrm{br}}$

Crack closing contribution due to intact fibres

$V_{f f}$

[MPa mm]

[MPa mm]

[MPa mm]

[MPa mm]

[MPa mm]

[MPa mm]

[-]

[-]

[-]

$[-]$

[-]

[N]

[mm]

[mm]

[mm]

[MPa]

[mm]

[mm] stresses 


$\begin{array}{lll}\delta_{\mathrm{f}} & \begin{array}{l}\text { Elongation of fibres due to ten- } \\ \text { sile fibre stresses }\end{array} \\ \delta_{\mathrm{pp}} & \begin{array}{l}\text { Elongation component related } \\ \text { to shear deformation }\end{array}\end{array}$

\section{Introduction}

The fatigue crack growth and fracture behaviour of Fibre Metal Laminates (FMLs) have been extensively investigated in the past decades. The majority of papers being published on these topics report fatigue and fracture experiments on various coupon specimens, analysis of observation and development of understanding by means of empirical or theoretical models (Marissen 1988; Takamatsu et al. 1999, 2003; Guo and Wu 1998, 1999; Alderliesten 2007a). Other papers originate from the theoretical fracture mechanics background and attempt to develop theoretical models describing the phenomena based on mathematical derivations rather than experimental observations (He and Hutchinson 1989; Dollar and Steif 1991; Lu 1996; Chan et al. 1993; Suiker and Fleck 2004, 2006).

Suiker and Fleck (2004) for example, published a paper in this journal some years ago describing the fracture mechanisms of laminates with isotropic constituents of which some layers contain mode I cracks and interfaces exhibit delamination growth. This description, based upon static fracture considerations for the deflection of a tunnelling crack at an interface, ignores fundamental phenomenological descriptions of fatigue fracture in such materials.

The authors of the present paper have developed an alternative fracture mechanics based approach to the prediction of fatigue crack growth in FMLs which has been previously published (Alderliesten 2007a). Based on the experience gained in the development of this approach and the wealth of experimental data and observation of fracture in FMLs, some comments can be made on the approach of Suiker and Fleck for static failure, as well as for fatigue fracture reported later in another journal (Suiker and Fleck 2006). This paper provides a critical review of the theoretical approach taken by Suiker and Fleck and highlights the dangers in applying mathematical descriptions to real phenomena without consideration for observable behaviour of the particular phenomena.

\section{Theoretical background}

The fracture behaviour in monolithic metal sheet applications under static and fatigue loading has been extensively investigated in the past and theoretical descriptions based on Stress Intensity Factors have been documented (Tada et al. 2000). Depending on the thickness of the sheets, either plane stress or plane strain states have been observed, which have effect on the fracture properties, especially for fatigue crack growth (Schijve 2001).

To increase the fatigue behaviour of aircraft structures, the FML concept has been developed. This concept exploits the fatigue benefits of a plane stress state by utilizing thin metallic sheets laminated with a reinforcing fibre layer. The fibre layer further enhances fatigue behaviour by bridging load around cracked metallic layers, effectively reducing the Stress Intensity Factor of the crack tip.

The overall fracture process in FMLs comprises of a complex interaction of several mechanisms. First, metallic layers crack under mode I loading in a manner analogous to monolithic metallic materials. Second, a delamination between the interfaces of the cracked aluminium and adjacent fibre layers occurs as a result of the large shear stresses that form as the intact fibre layer attempts to match the strain due to crack opening. The shape and size of the resulting delamination determine the extent of the bridging effect of the fibre layers and the resulting Stress Intensity Factor reduction for the crack tip in the metallic layers. Delamination shape and size thus influence the crack growth rate. In turn, further crack extension results in further delamination extension. As a result, crack extension, delamination growth, and crack opening displacement are interdependently linked in the fracture process of FMLs.

From an engineering perspective (or from an experimental practice), the bridging effect of the fibre layer has been taken as fact, on which further analysis and model development has been based (Marissen 1988; Takamatsu et al. 1999, 2003; Guo and Wu 1998, 1999; Alderliesten 2007a). The fibre layers are insensitive to the occurring fatigue stresses and bridge the crack. The crack remains in the metal layer without penetrating the fibre layers, but deflects at the interfaces as delamination growth.

From a theoretical fracture mechanics perspective, the deflecting phenomenon itself is of interest and has 
become subject of investigation and analysis. He and Hutchinson (1989) have developed general criteria describing the crack deflection at the interfaces. They assume that both fracture modes (penetration or deflection) are in competition and that the relative toughness defines the crack path.

In general, these theoretical approaches generate more quantitative insight in the observed phenomena. However, one has to carefully evaluate the assumptions with experimental observations before applying the theory to any laminated composite. For example, in many laminated composites in general and in FMLs in particular, the interface itself is not clearly defined a priory. The position of the interface has to be validated with experiments; that is at which location the delamination occurs. This aspect will be discussed further on in this paper.

In addition, the theory of $\mathrm{He}$ and Hutchinson has been based on static fracture considerations, which might not automatically translate to fatigue related phenomena.

More theoretical research has been published on $\mathrm{H}$-shaped crack geometries in infinite laminated composites, in general of elastic nature (Dollar and Steif 1991; Lu 1996) although some report inclusion of plasticity (Chan et al. 1993). Most of the theoretical models have been derived for elastic brittle materials coming from the background of fibre-reinforced ceramic composites. Under the same assumption of considering elastic and brittle materials, Suiker and Fleck $(2004,2006)$ have derived failure maps for FMLs describing the crack tunnelling and delamination behaviour.

The application of the theory as presented by Suiker and Fleck is based on a 2D-approach describing the competition between a crack penetrating the adjacent layer and a deflection of a crack as a delamination between the interfaces, see Fig. 1. In the discussion of possible mechanisms, a translation of this 2D-problem to a 3D-problem has been made, where a crack is tunnelling in the third direction, see Fig. 2. The authors justify this translation with the argument that the difference in strain energy upstream and downstream can be equated to the delamination work downstream.

However, looking at the experimental evidence, especially the 3D-fatigue crack configuration to which the authors refer, there seems to be a discrepancy between the theory and fracture behaviour observed in practice.

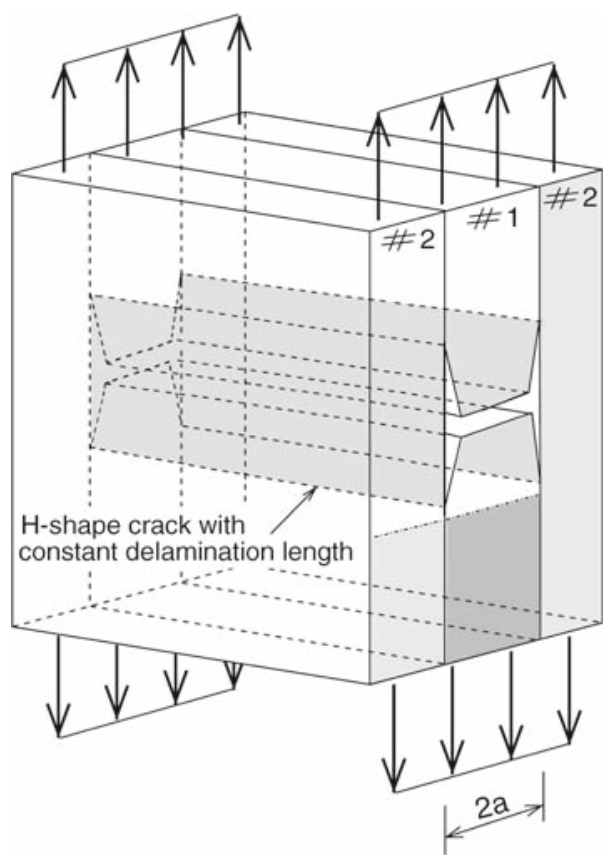

Fig. 1 Crack geometry considered by Suiker and Fleck

\section{Possible failure mechanisms}

The theoretical crack tunnelling mechanisms in Fig. 2 have been presented as static failure cases by Suiker and Fleck. In later work based on (Suiker and Fleck 2004) a similar analysis has been applied to fatigue crack propagation and delamination cases (Suiker and Fleck 2006). As mentioned earlier, the theory for static fracture does not automatically apply to fatigue related phenomena. To validate the applicability of the theory to fatigue crack propagation and delamination growth in FMLs the authors seem to provide insufficient validation with experiments.

\subsection{Mechanism 1}

The first mechanism containing a crack in the metal layer without delamination at the interfaces seems to be impossible for static as well as fatigue cases. As explained by Marissen (1988), the stress singularity at the interface gives infinite shear stresses, once the crack in the metal layers opens. The crack opening induces locally infinite strain of the adjacent layers at the location of the crack, which can not be followed by these layers. 


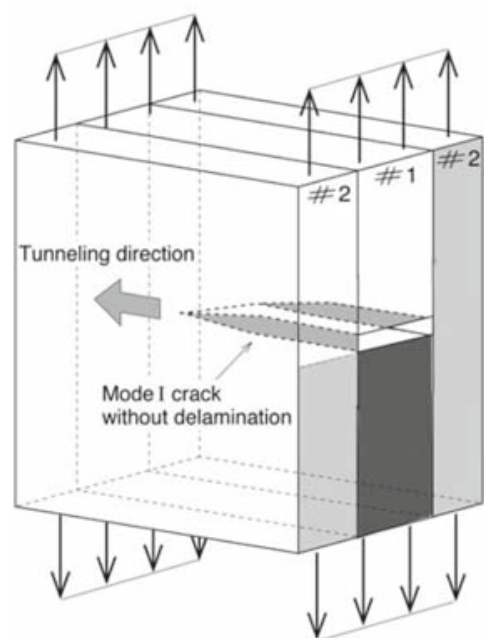

Mechanism 1

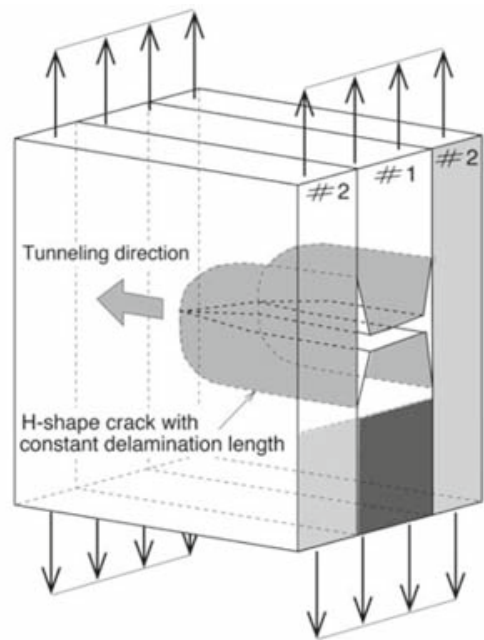

Mechanism 2

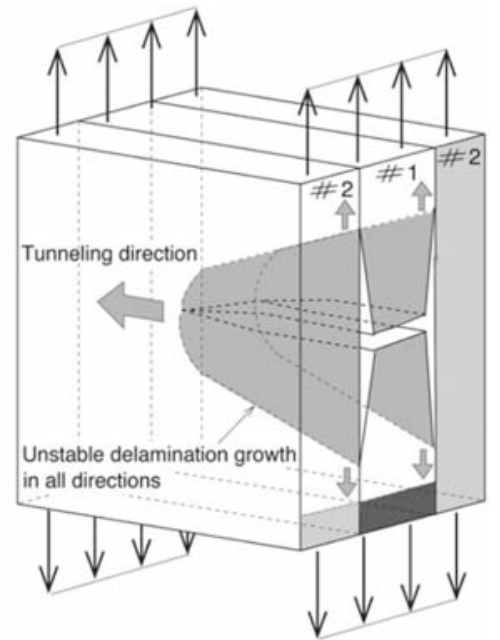

Mechanism 3

Fig. 2 Three theoretical failure mechanisms for static failure (Suiker and Fleck 2004)

Fig. 3 Example of a through-thickness fibre distribution in Arall (left) (Roebroeks 1991) and Glare (right) (Alderliesten et al. 2007). The resin rich layer at the interface in Arall is not present in Glare

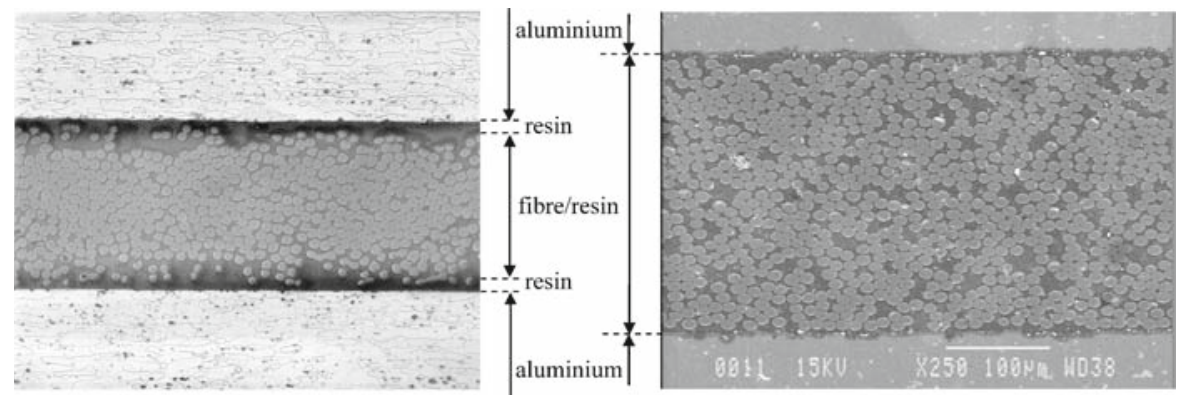

It depends on the composition of the adjacent fibre/ resin layers, how the layers deform under shear and whether cracks penetrate or immediately deflect as delamination to enable the layers to strain with the crack opening. In the case of FMLs, there is a difference between fracture behaviour of for example Arall (Marissen 1988) and Glare (Alderliesten et al. 2007). The Arall laminates contained a resin rich layer at both sides of the fibres at the interface with the aluminium layer as result of the manufacturing process (Roebroeks 1991), while the Glare laminates being cured with prepreg exhibit fibres evenly distributed over the total fibre layer. As a result the through-thickness deformation of the fibre layers is different for the two materials. The resin rich layers in Arall will crack along with the crack in the metal layers, reducing the locally high stress peaks, while in Glare the layers immediately delaminate to reduce the peak stresses (Alderliesten et al. 2007).
Note that Fig. 3 is an illustration of the fact that the interface used in the theoretical models is not clearly defined for all laminates. Depending on the constituents and the manufacturing processes the interface might be different. As a consequence, the behaviour might be different as well.

\subsection{Mechanism 2}

In theory, the second mechanism could be a possible failure mechanism for static load cases. However, for the case of fatigue crack propagation and delamination growth this mechanism seems unlikely. To obtain this mechanism the delamination growth rate should become zero in the wake of the tunnelling crack, which is only possible if a delamination growth threshold exists. Such delamination growth threshold has not been observed or reported so far. From the evidence 


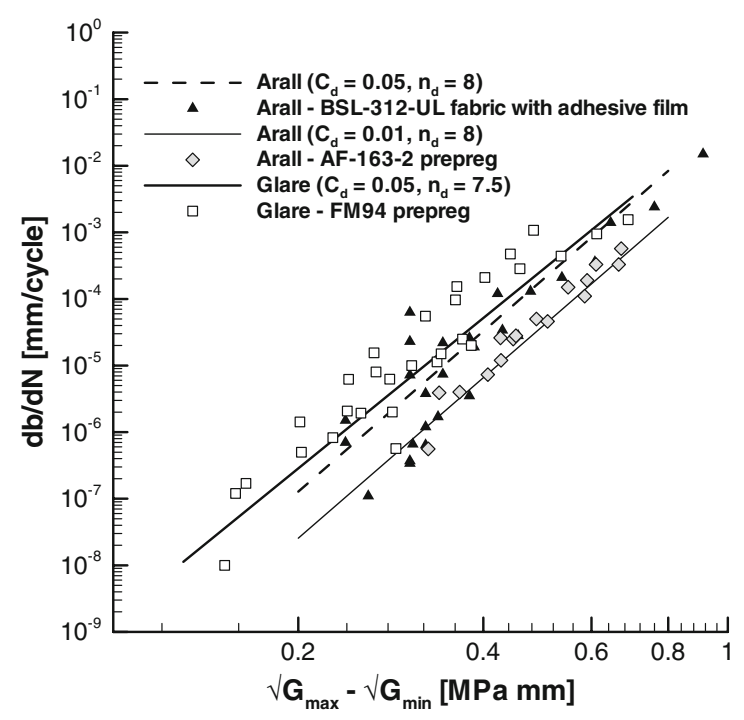

Fig. 4 Delamination growth curves for two aluminium-aramid fibre FMLs data from Marissen (1988), one aluminium-glass FML (Alderliesten et al. 2006)

available for various FMLs, see Fig. 4, the assumption of such fatigue threshold cannot be justified.

\subsection{Mechanism 3}

In principle, mechanism 3, illustrated in Fig. 2, might be correct for static failure cases, although that will be difficult to observe during experiments. The tunnelling crack growth rate could be so high as result of final fracture, that the amount of energy released, induces dynamic phenomena and instantaneous unstable delamination growth. The final fracture could (depending on the material properties; crack- and delamination-resistance) as well occur in the opposite sequence: unstable delamination growth resulting in final failure of the metal layers. One should note that the dynamic aspects are not considered in any of the theoretical models presented in He and Hutchinson (1989), Dollar and Steif (1991), Lu (1996), Chan et al. (1993), Suiker and Fleck (2004), Suiker and Fleck (2006).

de Vries (2001) reported residual strength tests, where stable tunnelling cracks were accompanied by stable delamination growth. Apparently, the three mechanisms as illustrated in Fig. 2, are not the only mechanisms that might occur during quasi-static and fatigue loading, as among others is illustrated with the residual strength tests of de Vries.
The fact that the theoretical models do not account for stable damage growth might be attributed to the quasi-static approach of the crack tunnelling and delamination fracture analysis, based on Griffith's theory

$\frac{G_{d}}{G_{I}}=\frac{G_{d c}}{G_{I c}}$

where $G_{d}$ is the strain energy release rate (SERR) for delamination and $G_{I}$ is the mode I SERR for the tunneling crack (subscript 'c' denotes the critical failure level).

The sequence in which delamination initiates and some extension occurs after which a new balance is formed is not considered with this relation. The reason is that Eq. 1 is based on the 2D-approach, illustrated in Fig. 1, while the rebalancing results from stress redistribution in a more complex 3D-manner.

\section{Effect of opening mode on delamination growth}

Suiker and Fleck report that the mode mixity can be calculated for various laminate configurations. With the so-called H-shape crack in the centre of a laminate with a 5/4 lay-up, a near mode II delamination mode has been calculated, while a configuration with the outer layers cracked, contains a significant mode I contribution. In theory, the total energy release rate must be calculated incorporating both modes in order to determine the delamination growth at the interface. It should then be expected from Suiker and Fleck (2004) that the delamination growth for the delamination at the outer interfaces is significantly higher than the $\mathrm{H}$-shape crack in the centre of the 5/4 lay-up.

However, experimental evidence shows clearly that the delamination growth rates observed during fatigue testing the centre crack in the 5/4-lay-up $\left(\Psi \approx 90^{\circ}\right.$ Suiker and Fleck 2004) and the surface cracks in the 2/1 lay-up ( $\Psi \approx 53^{\circ}$ Suiker and Fleck 2004) are similar Alderliesten et al. (2006). No clear contribution of the calculated mode I can be observed in the delamination growth tests, see Fig. 5.

Marissen (1988) has stated before that the calculated mode I opening mode does not contribute to the delamination growth under fatigue loading. The delamination growth is only induced by the mode II opening mode.

An example of the error that can be made when incorporating the mode I contribution to the total SERR 


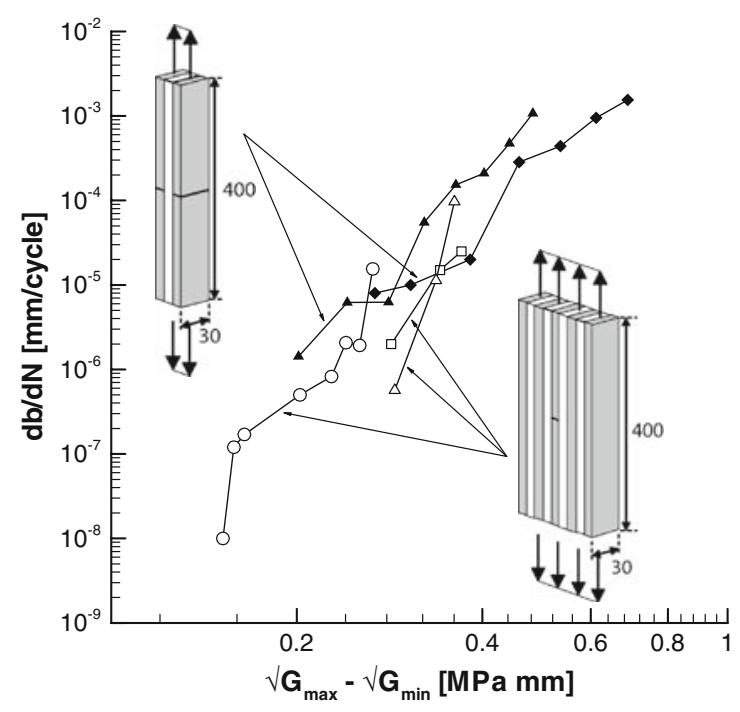

Fig. 5 Delamination growth curves for two Glare specimen configurations: Mode II centre crack in 5/4 lay-up (left) and Mixed-mode surface cracks in a 2/1 lay-up (right), indicating that the mode I has no influence on the delamination growth rate (Alderliesten et al. 2006)

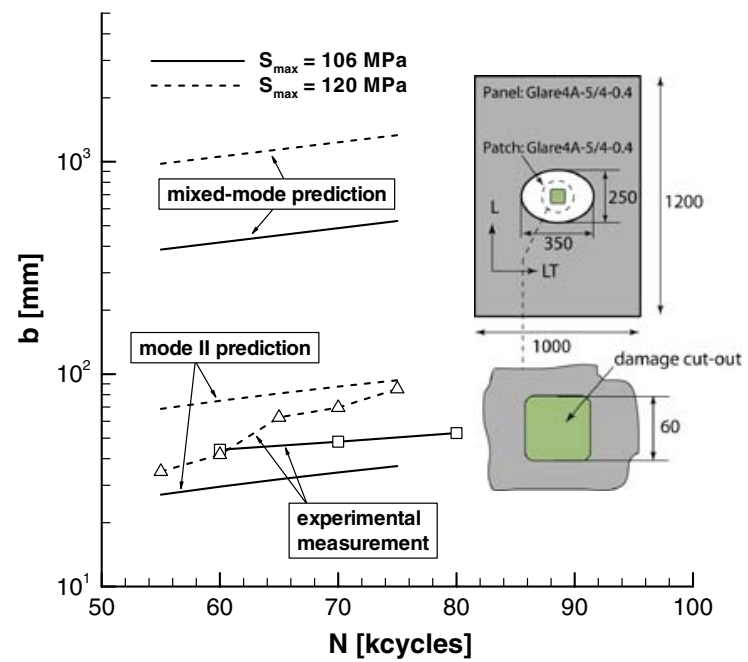

Fig. 6 Comparison of delamination growth underneath a repair patch with predictions based on either mode II SERR or mixedmode SERR (Alderliesten 2007b)

is given in Fig. 6, where the calculated delamination growth underneath a patch repair is compared with the observed delamination growth reported in Beumler (2004). The two cases are based on the total SERR, which consists either of the mode II SERR only, or it consists of both mode I and mode II.

Both SERR are related to the occurring peak and peel stresses
$G_{I}=\frac{t_{a d}}{2 E_{a d}} \sigma_{\max }^{2}, \quad G_{I I}=\frac{t_{a d}}{2 G_{a d}} \tau_{\max }^{2}$

for which the derivation has been made based on the theories presented in Hart-Smith (1973), Tong (1996), Lee and Kim (2005), Setoodeh et al. (2005), Qin and Dzenis (2003). Only the prediction based on the calculated mode II opening mode correlates quite well with the observed delamination growth underneath the patch repair, while the prediction based on the mixed mode overestimates the delamination growth rate by a factor of at least 10 . This clearly indicates that he calculated mode I does not contribute to the fatigue delamination growth.

\section{Experimental validation with static fracture tests}

Suiker and Fleck provide a comparison with experiments reported by de Vries et al. (1999), of which the specimen geometries are given in Fig. 7a, c. The values for comparison are the static strengths of the specimens tested by de Vries. They assume a critical SERR of $\mathrm{G}_{d}$ $=0.6 \mathrm{Nmm}^{-1}$ to correlate the predictions to the tests by de Vries. Although the correlation seems excellent, this SERR value needs further experimental validation to prove the physical relevance.

In addition, the results from de Vries et al. (1999) with which the theory has been compared, are static strength failures, which are not necessary delamination failures. The metal constituents in the laminates reach the maximum material strength and fail in most cases before the critical delamination SERR has been reached. Furthermore, the metal layers have been reported to yield at significant lower strength levels than the strength levels used in the comparison, which might make the application of a linear elastic SERR inaccurate.

In addition, de Vries reported delamination onset and growth at significant lower values than the static strength values. In fact, delamination extension occurred between the delamination onset strength and final fracture strength, which seems not to be considered with the Griffith's fracture criterion, see Eq. 1.

The results of de Vries are supported by Hooijmeijer (2002) who performed fatigue and residual strength tests on interlaminar doubler run-out specimens, see Fig. 7d, e. These configurations are in principle similar to the specimen configurations tested by de Vries. 
(a) $0^{\circ}$ fibres

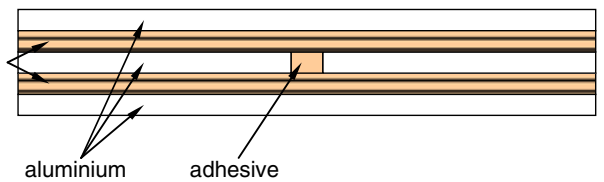

(b) $0^{\circ}$ fibres

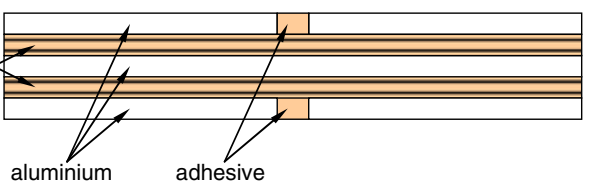

(c) $0^{\circ}$ fibres

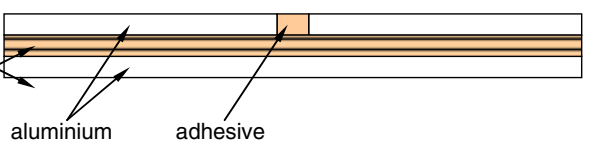

(d)

$0^{\circ}$ fibres

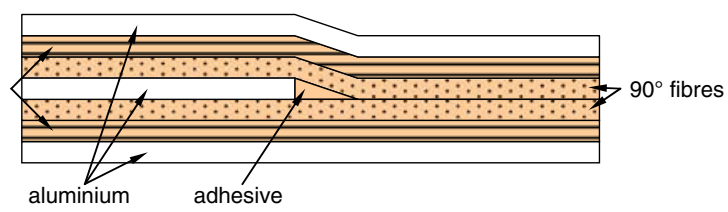

(e)

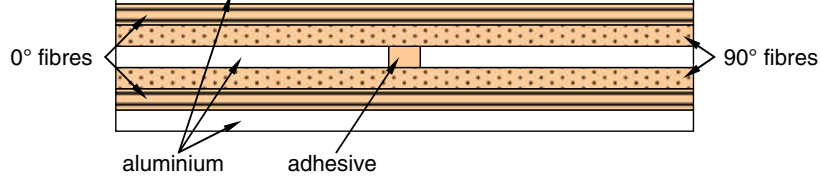

Fig. 7 Specimen geometries tested by de Vries [16] (a-c) and by Hooijmeijer (2002) (e, f)

The question is whether this delamination onset has been caused by the initial mode-mixity before the steady-state SERR has been reached. According to Suiker and Fleck the SERR asymptotes to the steady state value for $1 / a>1$. With the constituent thicknesses applied in FMLs de Vries et al. (1999), Alderliesten et al. (2006), Hooijmeijer (2002), this means that the observed delamination lengths (which are measured starting from the artificial crack) should have a length of at least $0.25 \mathrm{~mm}$. The delamination onset in Hooijmeijer (2002) has been reported for delamination lengths over $1 \mathrm{~mm}$, which is significantly beyond the $1 / \mathrm{a}>1$ threshold.

In other words, the Griffith's fracture criterion might be insufficient to describe the fracture mechanisms in FMLs under quasi-static and fatigue loading.

From an engineering perspective it can be argued that developing a method that ignores any plasticity is preferable if the predictions are sufficiently accurate. However, one has to be aware that ignoring plasticity itself, also omits any effect of plasticity on the delamination initiation and growth. In order to prove that the predictions in this case are accurate, the assumed critical SERR value needs to be substantiated. If this value can not be deduced from standardized fracture energy tests, see Fig. 8 and for example ASTM International (2001), the method is just a model empirically fitted to the test data.

The two different equations used in Suiker and Fleck (2004) to compute the steady-state stress in the aluminium layers for the two specimen configurations from de Vries et al. (1999) might give the impression that there is a difference in fracture behaviour. However, the energy balance method in principle only considers in-plane linear elastic behaviour ignoring any asymmetry effects, which is in fact the same approach as being used by other researchers in the past, such as for instance by Marissen (1988). This means that the only difference between the configurations with which the theory has been compared is the number of cracked aluminium layers.

This can be shown by rewriting the SERR relations presented in Suiker and Fleck (2004) in the form as reported in Alderliesten et al. (2006). The two SERR equations can be formulated in one single equation as

$$
\begin{aligned}
G_{d}= & \frac{S_{\text {lam }}^{2}}{2 j E_{a l}}\left[\gamma^{2}\left(n_{a l}-n_{c r}\right) t_{a l}-\lambda^{2} n_{a l} t_{a l}\right. \\
& +\frac{E_{f, 0}}{E_{a l}} n_{f, 0} t_{f, 0}\left(\gamma^{2}-\lambda^{2}\right) \\
& \left.+\frac{E_{f, 90}}{E_{a l}} n_{f, 90} t_{f, 90}\left(\gamma^{2}-\lambda^{2}\right)\right]
\end{aligned}
$$

with

$$
\begin{aligned}
\gamma & =\frac{t_{l a m}}{\left(n_{a l}-n_{c r}\right) t_{a l}+\frac{E_{f, 0}}{E_{a l}} n_{f, 0} t_{f, 0}+\frac{E_{f, 0}}{E_{a l}} n_{f, 0} t_{f, 0}} \\
\lambda & =\frac{t_{l a m}}{n_{a l} t_{a l}+\frac{E_{f, 0}}{E_{a l}} n_{f, 0} t_{f, 0}+\frac{E_{f, 0}}{E_{a l}} n_{f, 0} t_{f, 0}}
\end{aligned}
$$

where $n_{c r}$ is the number of cracked aluminium layers and $j$ the number of interfaces adjacent to cracked aluminium layers. This means that this theory can not 
Fig. 8 Four SERR test specifications to determine critical SERR: Mode I Double Cantilever Beam (a), Mode II End-notched Flexure (b), Symmetric Single-Leg BendingGII/G 0.4 (c), Mixed Mode Bending-any GII/G (d)
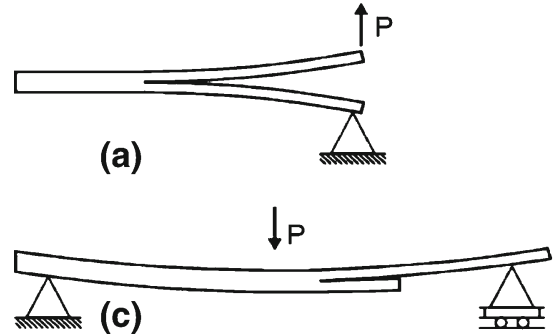

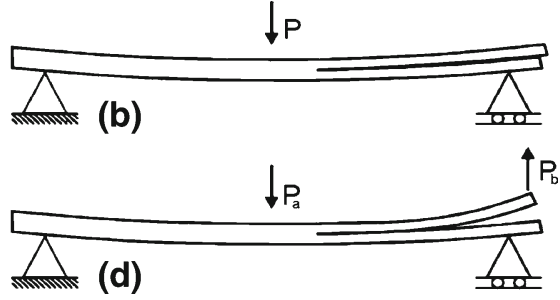

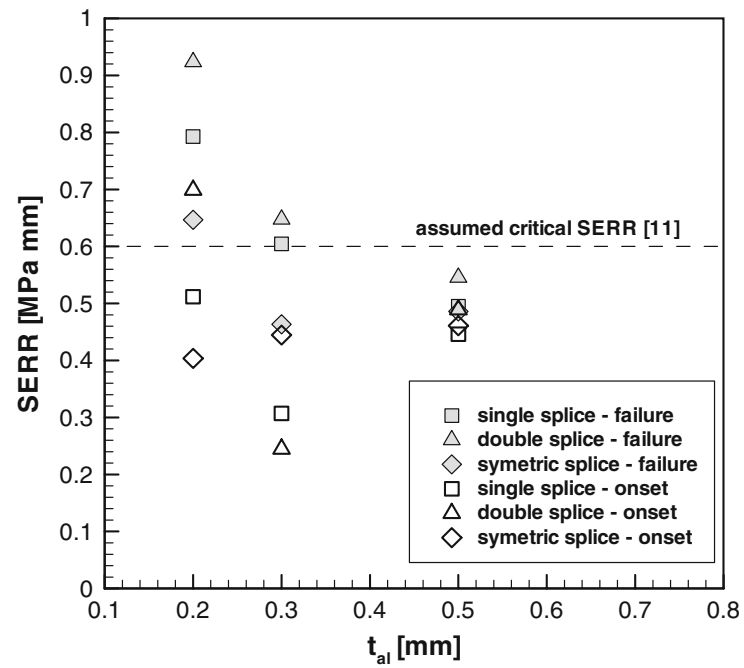

Fig. 9 Comparison between the onset and fracture SERR derived from the specimen configurations of de Vries et al. (1999) and the critical value assumed by Suiker and Fleck (2004)

only be compared with the two symmetrical specimen configurations in de Vries et al. (1999), but also with the asymmetric configurations if it is assumed that the effect of secondary bending is limited. The latter assumption can easily be validated by calculating the shift in neutral line at the location of the crack in the aluminium layer (Schijve 1972).

A comparison between the critical SERR assumed by Suiker and Fleck and the onset and fracture SERR derived from the tests of de Vries has been given in Fig. 9.

\section{$62 \mathrm{D}$ versus 3D analysis}

The theory on crack branching and kinking of cracks at interfaces (He and Hutchinson 1989; Dollar and Steif 1991; Lu 1996; Chan et al. 1993) has been derived in principle for two-dimensional crack configurations.
The translation of the theory from the two-dimensional configuration, illustrated in Fig. 1, to a 3D-configuration, as illustrated in Fig. 2, needs further research. The only argumentation seems to be that the difference in energy upstream and downstream can be equated to the work performed by the delamination in the wake of the crack. In theory, this assumption of energy balance between upstream and downstream might be justified. However, the way the delamination work is being performed along the wake of the crack still remains unknown, which makes any statement about the way the delamination progresses disputable.

\subsection{Delamination shape and bridging stress}

From the work of Marissen (1988) and Guo and Wu $(1998,1999)$ it has become clear that the crack opening restraint of the mode I tunnelling crack is significantly affected by the bridging stress in the wake of that crack. This bridging stress, initially assumed to be constant by Marissen, differs along the tunnelling crack length as shown by Guo and $\mathrm{Wu}$. The major parameter affecting the bridging stress is the delamination shape, which in itself is determined by the bridging stress. Especially the crack tip opening of the tunnelling crack is affected by the delamination shape and local bridging stresses near the crack tip. This is illustrated with the bridging stresses calculated for four different typical delamination shapes in Fig. 10 of a fatigue crack of $25 \mathrm{~mm}$ in a typical FML.

The delamination growth is related to the local shear stresses at the interface between aluminium and fibre layer, which directly follows from the load transfer, i.e. bridging stress, at that interface. The delamination growth will therefore vary along the tunnelling crack and the work performed to propagate that delamination shape requires a more complex approach than can be given by the two-dimensional description. 


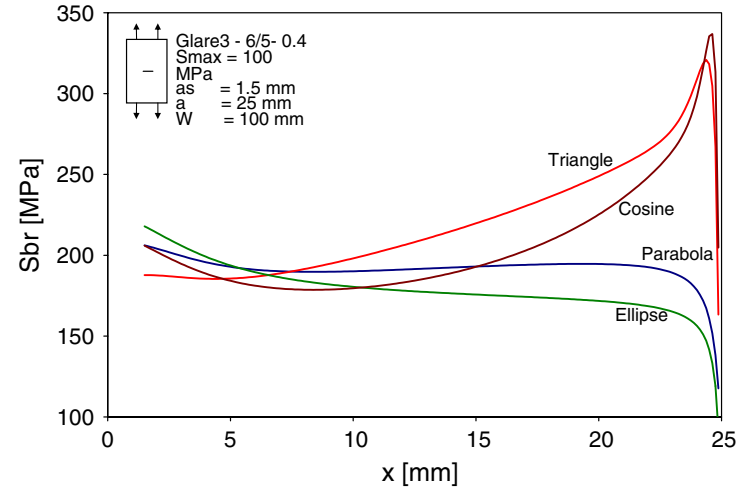

Fig. 10 Calculated bridging stress distributions for Glare3-6/50.4 in L-T direction with $\mathrm{W}=100 \mathrm{~mm}, \mathrm{a}=25 \mathrm{~mm}, \mathrm{a}_{s}=1.5 \mathrm{~mm}$ and $\mathrm{S}_{\max }=100 \mathrm{MPa}$ for the typical delamination shapes with $\mathrm{b}\left(\mathrm{a}_{s}\right) /\left(\mathrm{a}-\mathrm{a}_{s}\right)=0.2($ Alderliesten 2005)

In addition, the bridging stresses are dependent on the shear stiffness of the fibre/epoxy layers. The amount of shear deformation through the thickness of the layers, determines to some extent the local shear stress peak at the interface and the delamination growth rate. The previously mentioned difference between Arall and Glare, see Fig. 3, contributes to the shear deformation in the analysis.

Suiker and Fleck conclude that if the steady-state propagation condition is not reached, which is the basis of their analysis, the constant delamination length (mechanism 2 in Fig. 2) converts into a configuration where the delamination continuously propagates. Considering the above discussion and the experimental observations of fatigue delaminations at interfaces in various FMLs, it seems that a theoretical model based on steady-state propagation is rather limited.

\subsection{Stress ratio}

With respect to fracture mechanisms in FMLs, another aspect that need consideration is the presence of residual stresses. The difference in thermal expansion coefficients of the metal and fibre/epoxy constituents and the elevated curing temperature induces residual stresses in each layer. This means that when the fatigue crack propagation and delamination growth in FMLs is related to the mechanisms illustrated in Fig. 2, one has to consider that the stress ratio in the metal layer as well as in the fibre layer do not directly correlate to the applied stress ratio, $R=S_{\min } / S_{\max }$. This means that the case of fatigue loading with a stress ratio of $R=0$, the mode I SIF for the tunnelling crack and the mode II SIF for the delamination do in practice not reduce to

$$
\Delta K_{I}=K_{I, \max } ; \quad \Delta K_{d}=\left|K_{d}\right|_{\max }
$$

For example, from Alderliesten (2007a), Plokker et al. (2007) it is known that the stress ratio for the tunnelling crack and the delamination are not equal to each other and to the applied stress ratio. There, it is concluded that the difference in stress ratio is not only related to the residual stresses present in the laminate as result of curing, but that the major contribution comes from the bridging fibres closing the mode I tunnelling crack. This bridging effect changes the maximum and minimum SIF significantly (Plokker et al. 2007). As a result, the stress ratio for the tunnelling crack must be calculated based on the crack opening restraint contribution and separately, for delamination it must be calculated along the tunnelling crack length to account for the variation.

\subsection{Experiments validation}

To validate theoretical models with experimental research, careful attention should be paid to the selection of test results. The comparison of predictions with experimental results should prove that presented theory is supported by actual test data. One should keep in mind that obtaining good correlation between prediction and test does not automatically validate the prediction.

For example, the good correlation between experimental results from Marissen (1988) and the theory presented in Suiker and Fleck (2006) seems to validate the theory. However, Marissen and other authors (Guo and Wu 1999; Alderliesten et al. 2006) performed the delamination experiments to obtain the parameters in the Paris type relation between delamination growth and SERR, as illustrated in Fig. 4. In correlating the theory to these delamination experiments the opposite is done: the constants that should be derived from the tests are presented as input for the model, which is then correlated to the tests. By doing so, not the presented theory has been validated, but that selection of the constants for the Paris type relation.

To validate the theory itself, the Paris relation and constants obtained by Marissen or other authors should be used as input to predict different geometries or even 
3D-configurations for which data should be available or obtained.

\section{Effect of stress state}

In the theory of $\mathrm{He}$ and Hutchinson (1989) and Suiker and Fleck $(2004,2006)$ a plane strain stress state has been considered for both delamination at the interfaces and the tunnelling crack growth. However, the current FMLs, like Glare, which are also considered in Suiker and Fleck $(2004,2006)$ are made of thin aluminium sheets, of which the thickness ranges from 0.3 to $0.5 \mathrm{~mm}$, and fibre/epoxy layers with a thickness of $0.133 \mathrm{~mm}$.

The effect of the stress state on the fatigue life has been illustrated by Schijve et al. (1979), who reported fatigue tests on laminated aluminium alloy sheet material and monolithic aluminium of the same thickness. The effect observed in their tests is similar to the effect present in the thin aluminium sheets of an FML. The relatively soft epoxy layers can not prevent the metal layers to strain in thickness direction, which results in a plane stress state.

As a consequence, the plastic zones at the crack tip are larger with more crack closure and lower crack growth rates as result (Plokker et al. 2007). For the tunnelling fatigue crack configuration, this means that the analysis should not be performed using the plane strain values, but the plane stress values together with the appropriate Paris type relation between crack growth rate and effective stress intensity factor range.

However, when other hybrid materials are being considered, such as the recently presented lower wing skin material concept CentrAl (Roebroeks et al. 2007), this plane strain assumption might be justified. In these concepts thicker aluminium sheets are being bonded with fibre/epoxy systems to internal stiffening laminates.

\section{Proposed fracture mechanics approach}

From the previous discussion, it is evident that the fracture mechanisms within FMLs under static and fatigue loading are complex 3D-mechanisms that cannot easily be described using two-dimensional theories. The question thus arises how these mechanisms can be best described using the fracture mechanics theories available. In principle, two approaches could be followed.
The two-dimensional models discussed in this paper could be extended in crack tunnelling direction towards a 3D-description. The alternative route is to use the two-dimensional description as utilized by Tada et al. (2000), Ewalds and Wanhill (1984) where the plane of the tunnelling crack is being considered ignoring any effect in thickness direction. The solutions provided by Tada et al. (2000) provide a valuable means to describe the tunnelling crack including additional mechanisms related to intact fibre layers in the wake of this crack. The relations between applied load systems, crack opening shape, and SIF can be utilized in numerical models to describe the variation in bridging stresses and delamination length in the wake of the crack.

Here, the earlier mentioned disadvantage in extrapolating the two-dimensional theories into the tunnelling crack direction can be easily overcome. At any location in the wake of the crack, the crack closing contribution of the intact fibre layers can be described with a point-load system at a distance away from the crack equal to the delamination length at that location. Exact solutions can be obtained to correlate this crack closing contribution, often described in bridging stresses, to the delamination extension at that location and to the mode I SIF at the tunnelling crack tip.

The relation between delamination growth and the bridging stress at each location in the crack wake can be described using the SERR with relations similar to Eq. 3. This relation should be empirically determined correlating calculated values for the SERR and experimentally observed delamination growth rates. A simple test specimen configuration with the crack geometry as illustrated in Fig. 1 enables to use of the theories provided by He and Hutchinson (1989) and Suiker and Fleck $(2004,2006)$. Examples of this approach are presented by Marissen (1988) and Alderliesten et al. (2006). Note that the correlation performed by Suiker and Fleck (2006) with the data from Marissen is therefore not a validation, but a determination of the experimental relation between SERR and delamination growth using a power relation.

The earlier mentioned bridging stress, being the crack closing contribution of the intact fibre layers in the wake of the tunnelling crack, can be determined by correlating the elongation of the fibres over the delaminated length with the opening of the tunnelling crack. The crack opening as result of far field stress in the metal layers and the crack closing contribution by the fibres can be written as 
Fig. 11 Centre crack configuration in a FML with starter notch (saw-cut metal and fibres)

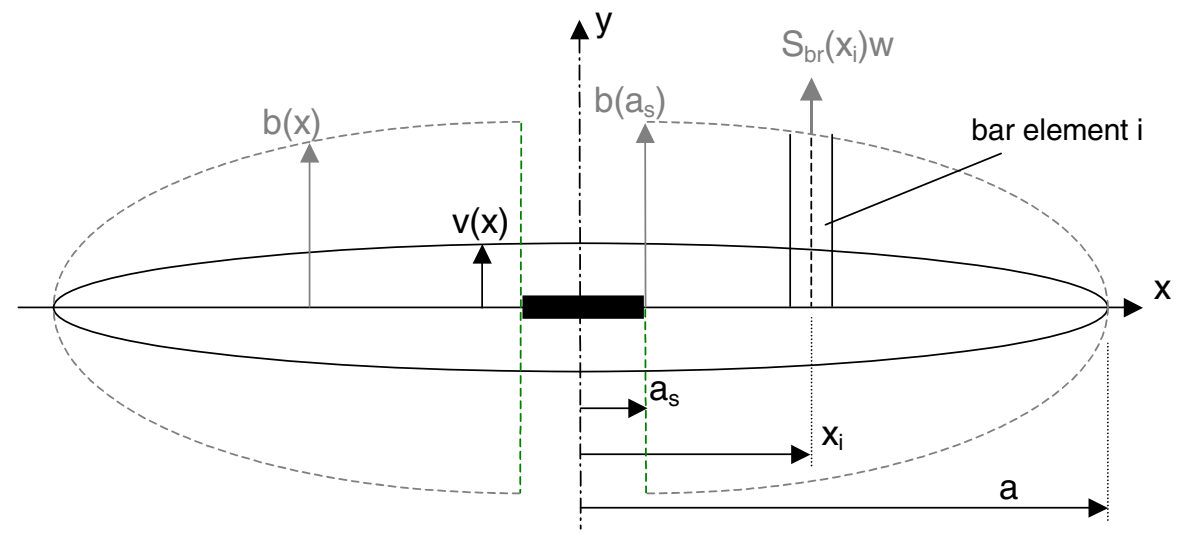

$v(x)=v_{f f}(x)-v_{b r}(x)$

The correlation with the fibre strain is then given by

$v(x)=\delta_{f}(x)+\delta_{p p}(x)$

where $\delta_{f}$ is the elongation of the fibre layer related to the tensile fibre stress and $\delta_{p p}$ the elongation related to the through-thickness shear deformation of the fibre layers. The crack configuration that can be then considered is illustrated in Fig. 11.

The advantage of this proposed approach is that is deals with several aspects discussed in this paper. First of all, because the tunnelling crack growth is described by a mode I SIF at the crack tip of a particular metal layer, the empirical relationship between crack growth rate and SIF range for a monolithic metal can be utilized. For most metals, this data has been published or is represented by a Paris-, Forman-, Priddle- or NASGRO relation (Paris and Erdogan 1963; Forman et al. 1967; Priddle 1972; NASGRO). Plasticity induced crack closure considerations related to small scale yielding at the crack tip therefore also apply to the proposed fracture mechanics description (Plokker et al. 2007).

The second advantage is that steady state propagation of the tunnelling crack is no longer required. The balance between delamination growth and tunnelling crack growth remains present at all times, independent of the delamination shape, which enables calculation of the progression of both damage mechanisms for many configurations. For fatigue cracks starting from a starter notch or open hole for instance, initial fast crack growth has been observed that decreases until the steady state has been reached. This initial fast crack growth is captured by the proposed description. This can be proven by comparing predicted and measured crack growth for a large $500 \mathrm{~mm}$ wide panel with a $75 \mathrm{~mm}$ initial starter notch. The initial deceleration of crack growth is followed by accelerated crack growth as result of final width effects, as shown in Fig. 12. This means that the steady state propagation level is not reached or maintained during the fatigue life. Nevertheless, the prediction based on the proposed approach easily corresponds with the observed behaviour.

A third advantage of the proposed approach is related to validation of the theory. Because the theory calculates not only crack growth and delamination growth, but also crack opening of the tunnelling crack, these three parameters can be directly compared with experimental observations. Figure 12 provides the comparison for the observed crack growth. The predicted crack opening contours for one of the tests in Fig. 12 are being compared in Fig. 13. A good correlation is evident. A similar comparison with delamination shapes, obtained at the end of the test by etching away the metal layers, is given in Fig. 14.

\section{Conclusions}

The tunnelling crack propagation and delamination growth in FMLs has been used in this paper to discuss the theoretical models on crack tunnelling and delamination in layered solids presented in the literature. It has been identified that for theoretical model development two approaches can be identified: the development of theoretical models based on mathematical derivation and logic analysis with in a later stage correlation with experiments. The other approach is to observe behaviour in experiments and to develop theoretical models describing the observed mechanisms. 
Fig. 12 Comparison between the predicted and measured crack propagation of Glare3-4/3-0.5 in L-T direction with $\mathrm{W}=500 \mathrm{~mm}$, as $=37.5 \mathrm{~mm}$ and $\mathrm{S}_{\max }=100$ and $120 \mathrm{MPa}$ with $\mathrm{R}=0.05$

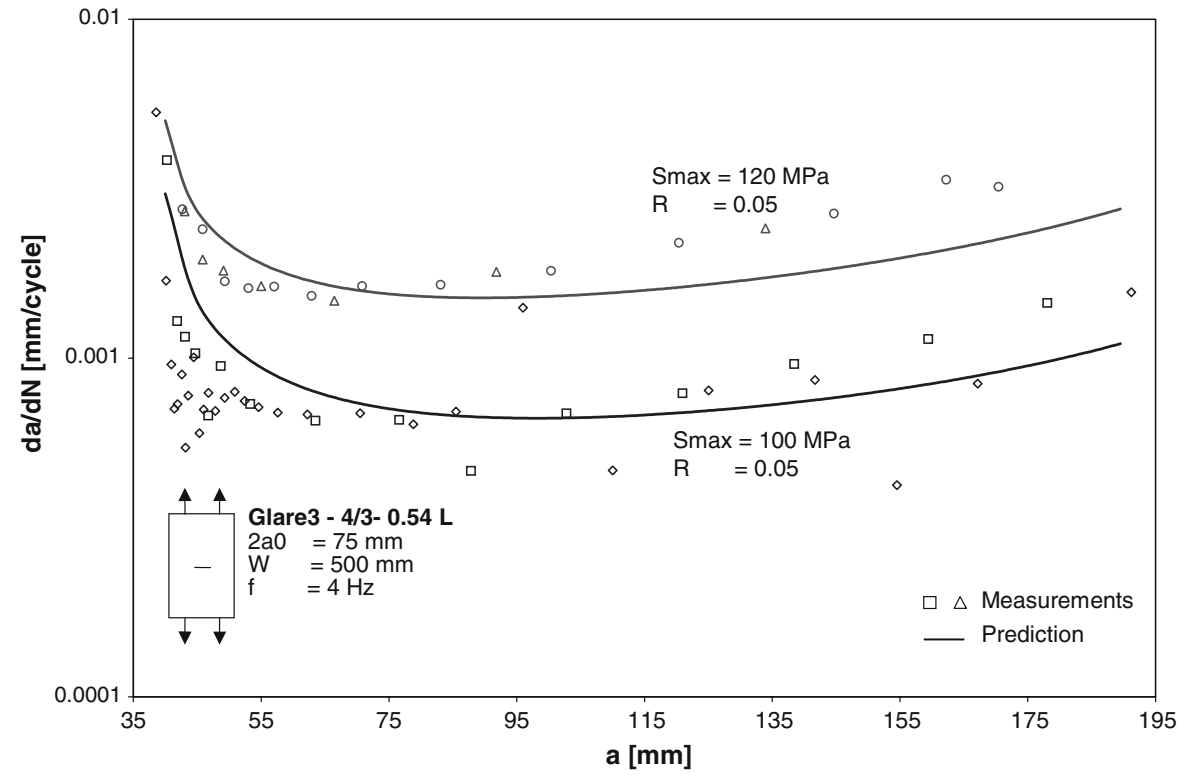

Fig. 13 Comparison between the predicted and measured crack opening displacement of Glare3-4/3-0.5 in L-T direction with $\mathrm{W}=500 \mathrm{~mm}$, as $=37.5 \mathrm{~mm}$ and $\mathrm{S}_{\max }=120 \mathrm{MPa}$ with $\mathrm{R}=0.05$

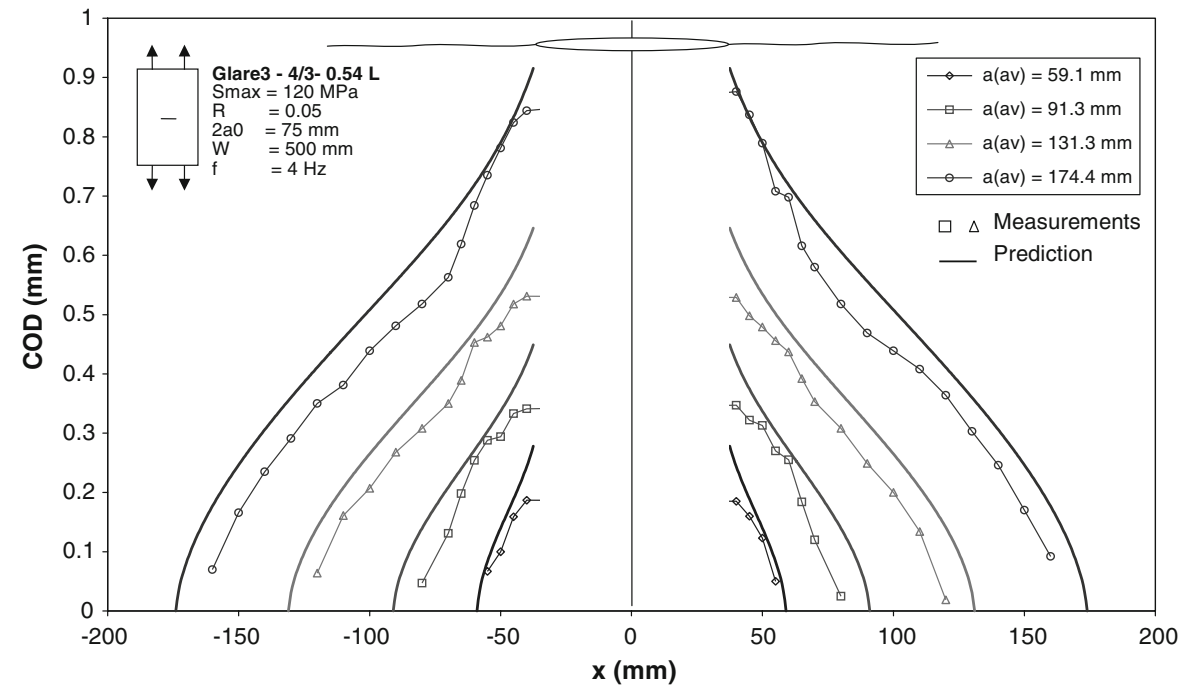

The theoretical models discussed in this paper originate from the first approach. Therefore the experience and experimental observations on fracture behaviour of FMLs have been used to evaluate the theoretical models. From this evaluation the following conclusions can be drawn:

- The theoretical models presented in the literature seem to be limited to linear elastic and brittle materials, whereas the application to current FMLs, like Glare, should account for ductile material behaviour.

- There are more fracture mechanisms observed in experiments than the three identified by current the- oretical models. Under static loading, delamination onset and growth has been observed at significantly lower values than the fracture toughness values. Stable static and fatigue crack growth is often accompanied by stable delamination growth.

- The mode-mixity derived from the theoretical models seems not to have any effect on the observed delamination growth. Delamination initiation might be affected by the mode I peel contribution, the fatigue delamination growth is only affected by the mode II shear mode.

- The interface considered in the theoretical model needs a clear definition for each FML considered. 
Fig. 14 Comparison between predicted and measured delamination shapes of Glare3-4/3-0.5 in $\mathrm{L}-\mathrm{T}$ direction with $\mathrm{W}=500 \mathrm{~mm}$, as $=37.5 \mathrm{~mm}$ and $\mathrm{S}_{\max }=100 \mathrm{MPa}$ with $\mathrm{R}=0.05$

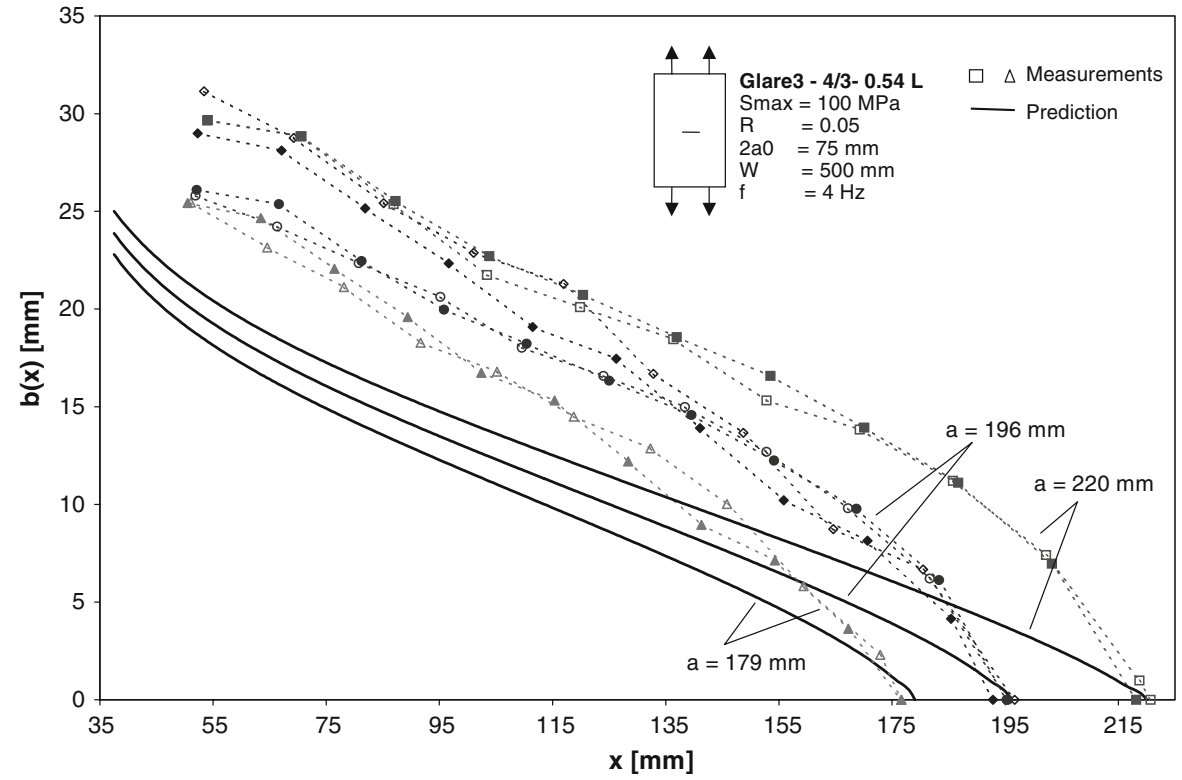

- The delamination resistance of the interface depends significantly on the adhesive system, which is often not considered in theoretical models.

- For current FMLs, the tunnelling crack propagates under plane stress conditions, instead of plane strain. For delamination at the interfaces, plane strain should be assumed.

- To facilitate design of laminates, fracture maps should be expressed in parameters that can be varied by the material developer. For fatigue crack propagation, however, fracture maps seem impractical.

- The two-dimensional approach seems to be limited applicable in its current form to static and fatigue cases in FML applications.

Another theoretical approach has been proposed that enables to describe the tunnelling crack growth and the delamination growth in the wake of the crack. The model is derived based on available solutions for crack in loaded sheets and has been validated with experimentally observed crack growth, delamination growth and crack opening profiles.

Open Access This article is distributed under the terms of the Creative Commons Attribution Noncommercial License which permits any noncommercial use, distribution, and reproduction in any medium, provided the original author(s) and source are credited.

\section{References}

Alderliesten RC (2005) Fatigue crack propagation and delamination growth in Glare. $\mathrm{PhD}$ dissertation, Delft University of Technology, 2005

Alderliesten RC (2007a) Analytical prediction model for fatigue crack propagation and delamination growth in Glare. Int $\mathrm{J}$ Fatigue 29:628-646

Alderliesten RC (2007b) Damage tolerance of bonded aircraft structures. In: Proceedings of the 1st international conference on damage tolerance of aircraft structures, Delft, The Netherlands, 2007

Alderliesten RC, Schijve J, van der Zwaag S (2006) Application of the energy release rate approach for delamination growth in Glare. Eng Fract Mech 73(6):697-709

Alderliesten RC, Campoli G, Benedictus R (2007) Modelling cyclic shear deformation of fibre/epoxy layers in fibre metal laminates. Compos Sci Technol 67(11-12): 2545-2555

ASTM International (2001) D 6671/D 6671M-06, Standard Test Method for Mixed Mode I-Mode II Interlaminar Fracture Toughness of Unidirectional Fiber Reinforced Polymer Matrix Composites. Annual Book of ASTM Standards, volume 15.03, 2001

Beumler Th (2004) Flying Glare ${ }^{\circledR}$, a contribution to aircraft certification issues on strengths properties in non-damaged and fatigue damaged GLARE ${ }^{\circledR}$ structures. PhD dissertation, Delft University of Technology, Delft

Chan KS, He M-Y, Hutchinson JW (1993) Cracking and stress redistribution in ceramic layered composites. Mater Sci Eng A $167: 57-64$

de Vries TJ (2001) Blunt and sharp notch behaviour of Glare laminates. PhD dissertation, Delft University of Technology, 2001 
de Vries TJ, Vlot A, Hashagen F (1999) Delamination behavior of spliced fiber metal laminates, Part 1-experimental results. Compos Struct 46(2):131-145

Dollar A, Steif PS (1991) The branched crack problem revisited. J Appl Mech (ASME) 58:584-586

Ewalds HL, Wanhill RJH (1984) Fracture mechanics. Delftse Uitgevers Maatschappij, Delft

Forman RG, Kearney VE, Engle RM (1967) Numerical analysis of crack propagation in cyclic loaded structures. J Basic Eng Trans ASME 89:459-464

Fracture Mechanics and Fatigue Crack Growth Analysis Software NASGRO ${ }^{\circledR}$, version 5.2 (2008) Southwest Research Institute, P.O. Drawer 28510, San Antonio, Texas 782280510

Guo YJ, Wu XR (1998) A theoretical model for predicting fatigue crack growth rates in fibre-reinforced metal laminates. Fatigue Fract Eng Mater Struct 21:1133-1145

Guo YJ, Wu XR (1999) Bridging stress distribution in centercracked fiber reinforced metal laminates: modelling and experiment. Eng Fract Mech 63:147-163

Hart-Smith LJ (1973) Adhesive-bonded single lap joints, Langley Research Center, NASA CR-112236, Hampton, Virginia

He M-Y, Hutchinson JW (1989) Crack deflection at an interface between dissimilar elastic materials. Int J Solids Struct 25(9): 1053-1067

Hooijmeijer PA (2002) Doubler run-out fatigue properties. Report B2V-02-16, Delft University of Technology, 2002 (restricted)

Lee J, Kim H (2005) Stress analysis of generally asymmetric single lap adhesively bonded joints. J Adhes 81:443-472

Lu TJ (1996) Crack branching in all-oxide ceramics composites. J Am Ceramics 79:266-274

Marissen R (1988) Fatigue crack growth in ARALL, a hybrid Aluminium-Aramid composite material, crack growth mechanisms and quantitative predictions of the crack growth rate. $\mathrm{PhD}$ thesis, Delft University of Technology

Paris PC, Erdogan F (1963) A critical analysis of crack propagation laws. Trans ASME Ser D 85:528-535

Plokker HM, Alderliesten RC, Benedictus R (2007) Crack closure in fibre metal laminates. Fatigue Fract Eng Mater Struct 30:608-620

Priddle EK (1972) High cycle fatigue crack propagation under random and constant amplitude loadings. Int J Press Vessels Piping 4:89

Qin M, Dzenis YA (2003) Analysis of single lap adhesive composite joint with delaminated adherends. Compos Part B 34(2):167-173
Roebroeks GHJJ (1991) Towards GLARE - the development of and fatigue insensitive and damage tolerant aircraft material. $\mathrm{PhD}$ thesis, Delft University of Technology

Roebroeks GHJJ, Hooijmeijer PA, Kroon EJ, Heinimann MB (2007) The development of Central. In: Proceedings of the 1st international conference on damage tolerance of aircraft structures, Delft, The Netherlands, 2007

Schijve J (1972) Some elementary calculations on secondary bending in simple lap joints, NLR-TR-72036, National Aerospace laboratory, Amsterdam, The Netherlands

Schijve J (2001) Fatigue of structures and materials. Kluwer Academic Publishers, Dordrecht

Schijve J, Van Lipzig HTM, Van Gestel GFJA, Hoeymakers AHW (1979) Fatigue properties of adhesive-bonded laminated sheet material of aluminium alloys. Eng Fract Mech 12:561-579

Setoodeh AR, Hadavinia H, Biglari FR, Nikbin K (2005) Comparison of analytical, numerical, and experimental methods in deriving fracture toughness properties of adhesives using bonded double lap joint specimens. J Adhes 81:529-553

Suiker ASJ, Fleck NA (2004) Crack tunnelling and plane-strain delamination in layered solids. Int J Fract 125:1-32

Suiker ASJ, Fleck NA (2006) Modelling of fatigue crack tunneling and delamination in layered composites. Compos Part A 37:1722-1733

Tada H, Paris PC, Irwin GR (2000) The stress analysis of cracks handbook, 3rd edn. The American Society of Mechanical Engineers

Takamatsu T, Matsumura T, Ogura N, Shimokawa T, Kakuta Y (1999) Fatigue crack growth properties of a GLARE35/4 fiber/metal laminate. Eng Fract Mech 63:253-272

Takamatsu T, Shimokawa T, Matsumura T, Miyoshi Y, Tanabe Y (2003) Evaluation of fatigue crack growth behaviour of GLARE3 fiber/metal laminates using compliance method. Eng Fract Mech 70:2603-2616

Thomas H, Mitrovic M, Turkgenc O (1999) The effect of loading parameters on fatigue of composite laminates: part III. Report DOT/FAA/AR-99/22, U.S. Department of Transportation, Federal Aviation Administration, Office of Aviation Research, Washington, DC 20591

Tong L (1996) Bond strength for adhesive-bonded single-lap joints. Acta Mech 117:101-113 